\title{
Research of Motor Soft Start by High Voltage Motor Drive Inverter
}

\author{
Jing Fang ${ }^{1}$, Le Zeng ${ }^{1}$, Qianqian $\mathrm{Li}^{1}$ \\ ${ }^{1}$ Chongqing Jianzhu College, Chongqing, P. R. China
}

\begin{abstract}
The over-current phenomenon of direct starting of high voltage and high power motor is serious bad for the safety of motor. We are usually using motor soft start method when we need to start a motor. There are some motor soft start methods, they can somehow reduce the starting over-current, but they are still having some defects except motor drive inverter. Motor drive inverter can not only realize the purpose of energy saving, but also is an ideal soft start device. We can see a lot of papers about control method research of motor drive inverter, but no paper research on motor soft start by motor drive inverter ${ }^{[1]}$. This paper focuses on research of motor soft start by motor drive inverter. The optimal frequency range of soft start is obtained through theoretical analysis. The simulation results verify the correctness and feasibility of the theoretical analysis.
\end{abstract}

\section{Introduction}

The direct starting current of high voltage and high power motor can reach 4-7 times of rated current. When the motor capacity is relatively large, the starting current will cause the power grid voltage to drop sharply and make the grid unstable. The high-order harmonic current of the starting current will cause the high frequency resonance of the circuit parameters of the power grid, and affect the normal operation of the other equipment of the power grid. For the motor itself, the heat generated by large current repeatedly acts on the insulation of the conductor, which makes the insulation aging and life reduced. When the high voltage switch is operated to close, the contact jitter phenomenon will produce the operating overvoltage on the motor stator winding, sometimes reaching 5 times of the applied voltage. So that the high overvoltage will cause great damage to the motor insulation ${ }^{[2]}$. In order to reduce or eliminate these hazards, motor soft start is usually used for the start of high voltage and high power motors.

The motor soft start can be divided into two types: multi-step and stepless. The former is regulated by stages, while the latter is regulated continuously. Previous soft start methods are all staged, such as $\mathrm{Y} / \triangle$ converter soft start, autotransformer soft start, reactor soft start, and so on. There are three kinds of stepless motor soft start: liquid resistance soft start, thyristor soft start and magnetic control soft start. There are obvious disadvantages in multi-step soft start, that is secondary impulse current will appear in the motor starting process, which has a bad impact to the power grid and motor. The liquid resistance soft start device can be connected in series in the rotor circuit of wound rotor motor to realize heavy-duty soft start. During the process of soft start, it does not produce high-order harmonic current, and the price is low, which is its outstanding advantages. However, due to the limited current of the liquid resistance, the large volume of the liquid resistance box and the poor repeatability of the soft start, the future of the liquid resistance soft start is not optimistic. Compared with the liquid resistance soft start, the thyristor soft start has the advantages of small volume, compact structure, almost maintenance free, complete functions, good starting repeatability and comprehensive protection, but it causes more serious high-order harmonic current. The magnetic control soft start is derived from the reactor soft start. The common point of these two is to use three-phase reactor series to reduce the voltage in the motor stator. The main difference between the magnetic control soft start and the reactor soft start is that its current limiting function is controllable. However, the magnetic control soft start needs a relatively high power auxiliary power supply, and the noise is also large.

Motor drive inverter can not only be used in energy saving and speed regulation of motor, but also an ideal soft start device, which can limit current and maintain high starting torque. In this paper, the soft start of motor drive inverter is studied. The calculation formula of the starting frequency is obtained through theoretical analysis. The starting frequency is calculated by combining with the actual motor parameters. The correctness and feasibility of the theoretical analysis are verified by comparing the simulation results of several typical frequencies through MATLAB / Simulink.

\section{Principal analysis of constant voltage frequency ratio control starting of high voltage motor drive inverter}

The control principle of high voltage motor drive inverter mainly includes constant voltage frequency ratio control, slip frequency control, space vector control and direct torque control ${ }^{[3]}$. The constant voltage frequency ratio

* Corresponding author: Jing Fang, 122566178@qq.com 
control system has the advantages of simple structure, low cost, and can meet the requirements of smooth speed regulation and low speed regulation accuracy. In this paper, constant voltage frequency ratio control soft start is studied.

The important factor need to be considered for motor speed regulation through frequency conversion is to keep the main magnet flux of the motor unchanged at the rated value ${ }^{[4]}$. If the magnet flux is too low, that the induced voltage will be too low. It will cause the motor iron core will not be fully utilized. As a result, the electromagnetic torque will be reduced, and the load capacity will be reduced. If the magnet flux is too high, that the induced voltage will be too high. As a result, the motor will be in over excitation state, and the motor will heat seriously due to the excessive excitation current. According to the principle of the motor, the effective value of each phase electromotive force of three-phase asynchronous motor stator is,

$$
E_{1}=4.44 f_{1} \mathrm{~N}_{1} \Phi_{\mathrm{m}}
$$

where $E_{1}$ is the effective value of electromotive force induced by air gap magnet flux in each phase of motor stator, $f_{1}$ is motor stator frequency, $\mathrm{N}_{1}$ is effective number of motor stator winding per phase, and $\Phi_{\mathrm{m}}$ is magnet flux per pole.

It can be seen from equation (1) that the value of $\Phi_{\mathrm{m}}$ is determined by $E_{1} / f_{1}$, but $E_{1}$ is difficult to control directly. Therefore, when the electromotive force is high, the motor stator leakage resistance voltage drop can be ignored and replaced by stator phase voltage $U_{1}$. That is to say, if $U_{1} /$ $f_{1}$ is always a certain value, then $\Phi_{\mathrm{m}}$ will not change.

According to the theory of electromotology, we know the relationship between the electromagnetic torque of asynchronous motor and phase voltage, frequency and slip ratio is ${ }^{[5]}$,

$$
T_{e}=\frac{m p U_{1}^{2} \frac{R_{2}^{\prime}}{s}}{2 \pi f\left[\left(R_{1}+\frac{R_{2}^{\prime}}{s}\right)^{2}+(2 \pi f)^{2}\left(L_{1}+L_{2}^{\prime}\right)^{2}\right]}
$$

where $m$ is motor phase number, $p$ is motor number of pole pairs, $U_{1}$ is motor phase voltage, $s$ is motor slip ratio, $f$ is power supply frequency, $\mathrm{R}_{1}$ and $\mathrm{L}_{1}$ is respectively motor stator resistance, and motor stator inductance, $\mathrm{R}_{2}$, and $\mathrm{L}_{2}{ }^{\prime}$ is respectively the rotor resistance is converted to the stator resistance, and the rotor inductance is converted to the stator inductance.

When the motor is powered on and the rotor is not rotate, the motor state is equivalent to locked rotor, $s=1$. If the starting frequency is $f_{\mathrm{S}}$, according to the constant $U_{1}$ $/ f_{1}$ control principle, $U_{1} / f_{\mathrm{S}}=U_{\mathrm{N}} / f_{\mathrm{N}}$, where $f_{\mathrm{N}}=50 \mathrm{~Hz}$. Equation (2) can be rewritten as follows,

$$
T_{e}=\frac{m p\left(\frac{f_{s} U_{N}}{50}\right)^{2} R_{2}^{\prime}}{2 \pi f_{s}\left[\left(R_{1}+R_{2}^{\prime}\right)^{2}+\left(2 \pi f_{s}\right)^{2}\left(L_{1}+L_{2}^{\prime}\right)^{2}\right]}
$$

When the motor starts with rated load, the load torque is the starting torque $T_{\mathrm{st}}$. Only when $T_{\mathrm{e}} \geq T_{\mathrm{st}}$, the motor starts to rotate. The starting frequency of the motor with rated load can be obtained by taking the actual motor parameters and load starting torque parameters into equation (3).

\section{Starting frequency calculation and simulation verification}

Motor parameters: three phase asynchronous motor, rated voltage $6 \mathrm{kV}$, rated current $54 \mathrm{~A}, \mathrm{R}_{1}=2 \Omega, \mathrm{R}_{2}{ }^{\prime}=1.9 \Omega$, $\mathrm{L}_{1}=7 / 100 / \pi, \mathrm{L}_{2}{ }^{\prime}=5 / 100 / \pi, \mathrm{L}_{\mathrm{m}}=235 / 100 / \pi, \mathrm{T}_{\mathrm{st}}=2735 \mathrm{~N}^{*} \mathrm{~m}$. Taking these parameters into equation (3),

$$
T_{e}=\frac{54720 f_{s}}{0.3619 f_{s}^{2}+95.5672} \geq T_{s t}
$$

so the answer is $5.28 \mathrm{~Hz} \leq f_{\mathrm{s}} \leq 50 \mathrm{~Hz}$. The starting frequency corresponding to the maximum starting torque is obtained by $T_{\mathrm{e}}$ doing derivative operation of $f_{\mathrm{s}}$ equal to 0 . The answer is $f_{\text {smax }}=16.25 \mathrm{~Hz}$.

Through MATLAB / Simulink, the relationship between starting frequency and electromagnetic torque is shown in Figure 1. According to the motor parameters, calculate the corresponding current when the starting frequency changes, and get the relationship between the starting frequency and the current, as shown in Figure 2, where the blue line is the effective value and the red line is the amplitude. The relationship between current and electromagnetic torque is shown in Figure 3.

It can be seen from Figure 1 that the maximum starting electromagnetic torque can be achieved when the starting frequency is about $16 \mathrm{~Hz}$. When the starting frequency is less than $16 \mathrm{~Hz}$, the starting electromagnetic torque is an increasing function of the starting frequency. When the starting frequency is greater than $16 \mathrm{~Hz}$, the starting electromagnetic torque is a decreasing function of the starting frequency. This is because when the frequency is low, the impedance of the motor itself plays a major role, and the inductive reactance is very small. When the frequency is high, because the impedance is constant, the inductive

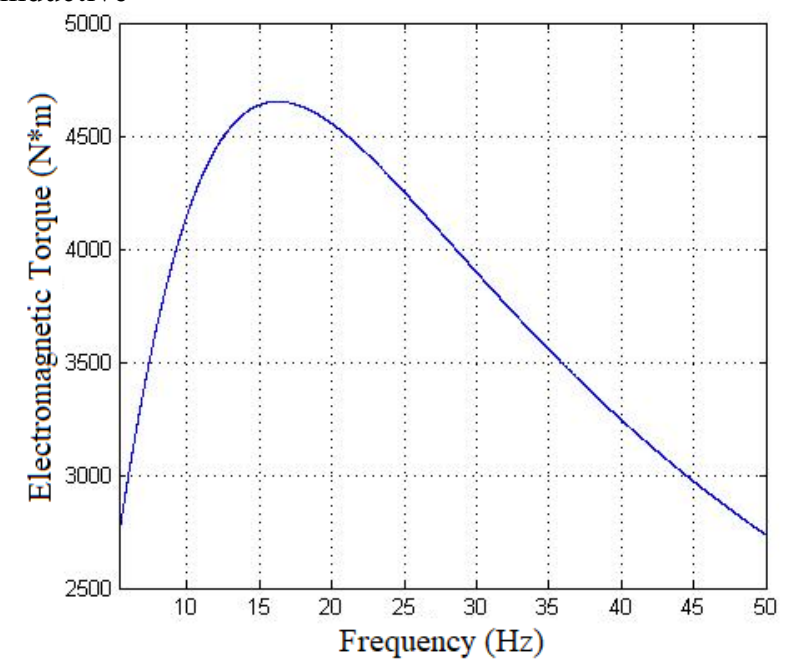

Fig. 1. Relationship between starting frequency and electromagnetic torque 


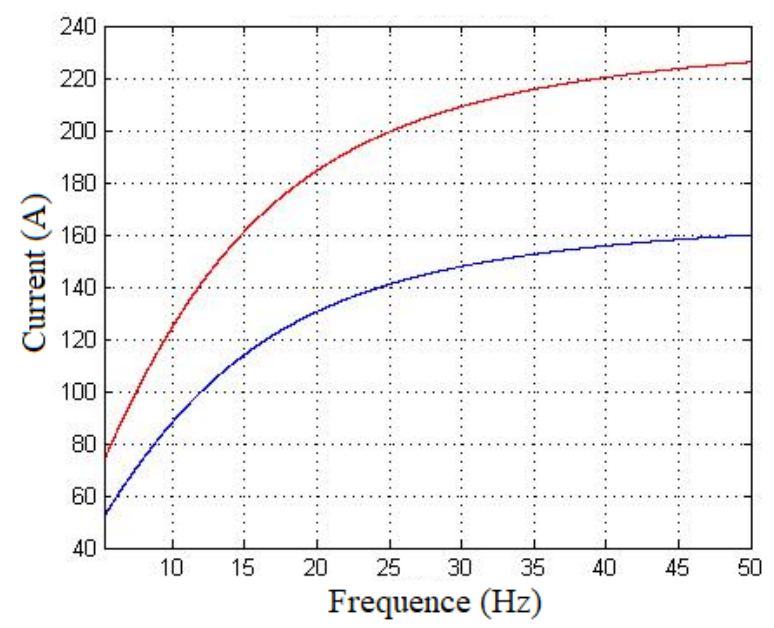

Fig. 2. Relationship between starting frequency and current

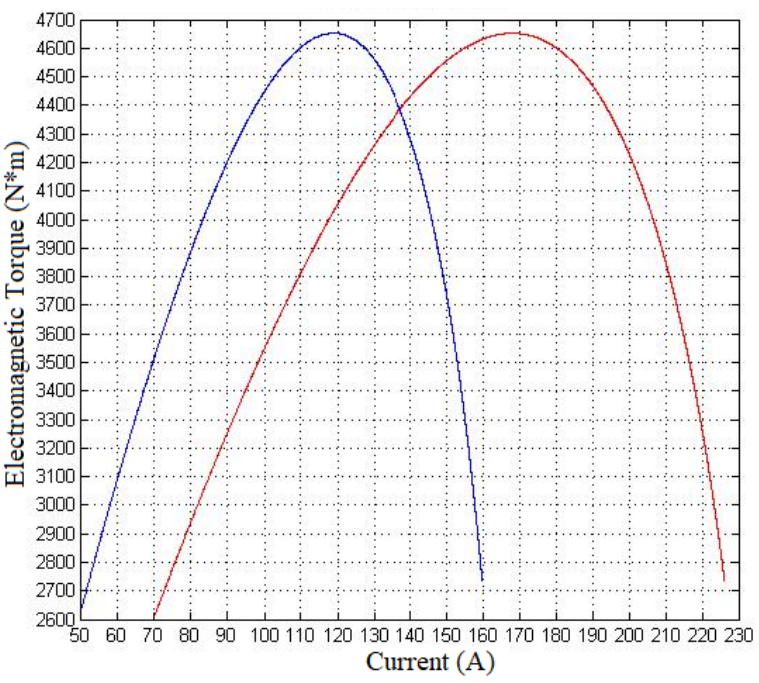

Fig. 3. Relationship between current and electromagnetic torque

reactance increases with the increase of frequency, and the inductive reactance is far greater than the impedance. It can be seen from Figure 2 that the current is an increasing function of starting frequency. With the increase of starting frequency, the current also increases. If the starting frequency is $5.28 \mathrm{~Hz}$, when the electromagnetic torque reaches the starting torque, the current is almost the rated current. If the starting frequency is $50 \mathrm{~Hz}$, when the electromagnetic torque reaches the rated torque, the current is three times of the rated current.

The simulation results of start frequency at $5 \mathrm{~Hz}, 16 \mathrm{~Hz}$ and $50 \mathrm{~Hz}$ are shows in Figure 4(a), (b), and (c). In the figures, the blue line is $5 \mathrm{~Hz}$ start condition, the green line is $16 \mathrm{~Hz}$ start condition, and the red line is $50 \mathrm{~Hz}$ start condition.

It can be seen from the comparative analysis that start frequency is respectively $5 \mathrm{~Hz}, 16 \mathrm{~Hz}$ and $50 \mathrm{~Hz}$ can all make the motor start with rated load. When the motor starts at $50 \mathrm{~Hz}$, the electromagnetic torque is very large and the rotor speed rises fast, but it produces 7 times overcurrent of rated current, and the electromagnetic torque oscillation is serious. When the motor starts at $16 \mathrm{~Hz}$, the rotor speed rises fastest and the stable operation time is the shortest, but it produces 3 times over-current of rated current, and the electromagnetic torque has 3 cycles of vibration. When the motor starts at $5 \mathrm{~Hz}$, the over-current is very small, about 1.4 times of rated current, the electromagnetic torque has no oscillation phenomenon, and the motor runs smoothly, meeting the requirements of soft start.

Several typical starting frequencies are simulated, and the simulation results are shown in Table 1.

It can be seen from the data in Table 1 that the time to reach the starting torque decreases with the increase of the starting frequency, and the maximum current increases with the increase of the starting frequency. The maximum electromagnetic torque of motor drive inverter starts at about $16 \mathrm{~Hz}$, and the time to reach the stability of the motor is the shortest at $16 \mathrm{~Hz}$. In order to achieve the purpose of soft start by using motor drive inverter, the maximum starting frequency should not exceed $f_{\text {smax }}$, but there will be about three times over-current of the rated current, and the electromagnetic torque will have three cycles of oscillation. The minimum starting frequency should not be less than $f_{\text {smin }}$, otherwise the electromagnetic torque cannot reach the starting torque, and the motor cannot start. The simulation results verify the theoretical calculation very well.

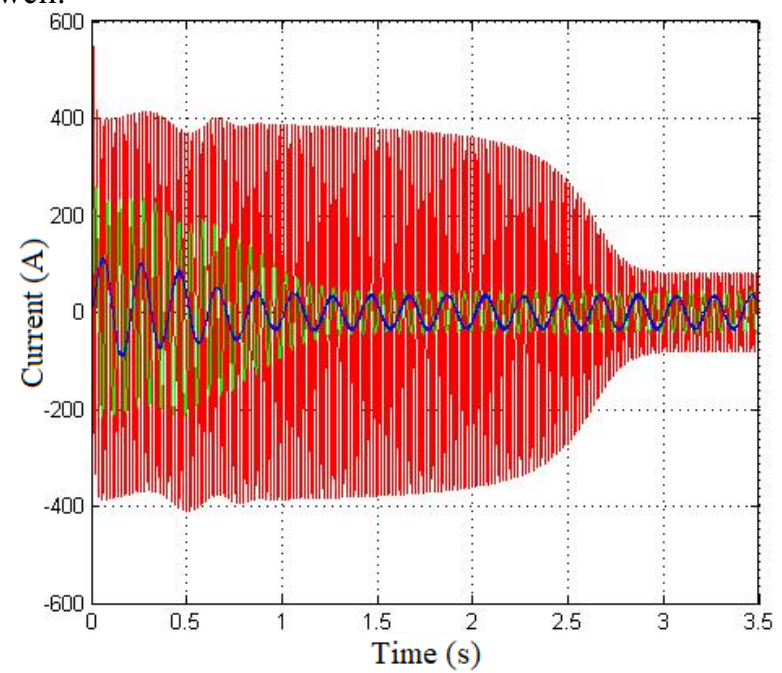

(a)

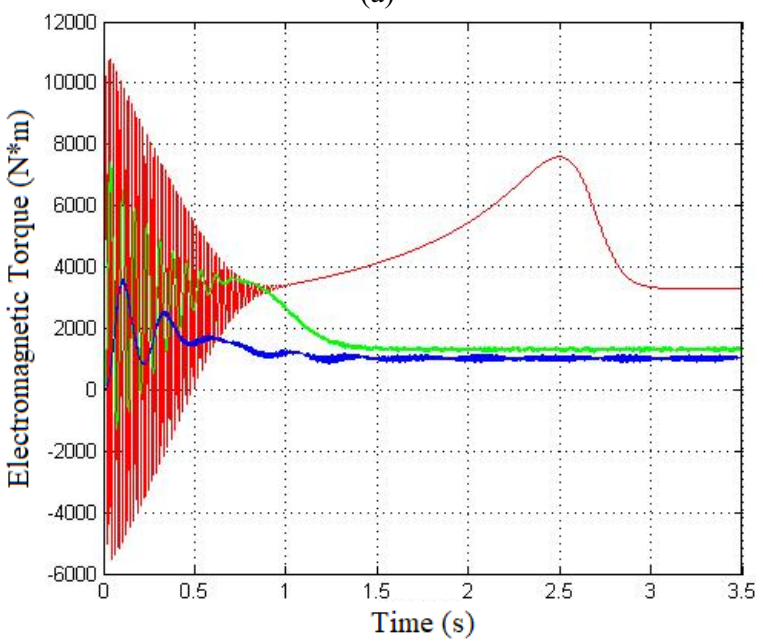

(b) 


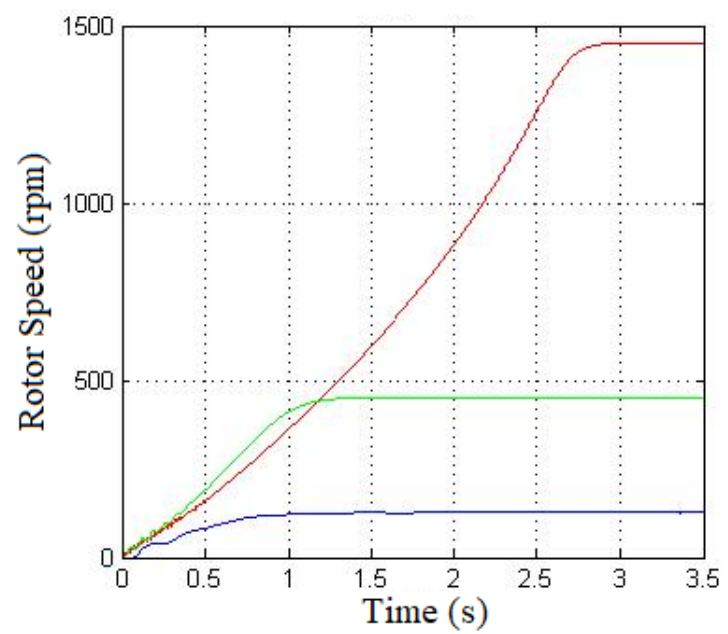

(c)

Fig. 4. Comparison graph of start frequency at $5 \mathrm{~Hz}, 16 \mathrm{~Hz}$, and $50 \mathrm{~Hz}$

Table 1. Start frequency simulation results

\begin{tabular}{|c|c|c|c|c|c|c|c|c|c|}
\hline Start frequency & $\mathbf{5 H z}$ & $\mathbf{1 0 H z}$ & $\mathbf{1 6 H z}$ & $\mathbf{2 0 H z}$ & $\mathbf{3 0 H z}$ & $\mathbf{3 5 H z}$ & $\mathbf{4 0 H z}$ & $\mathbf{4 5 H z}$ & $\mathbf{5 0 H z}$ \\
\hline Time to reach $\boldsymbol{T}_{\mathbf{s}}(\mathbf{s})$ & 0.077 & 0.0335 & 0.0215 & 0.018 & 0.0125 & 0.0116 & 0.0098 & 0.00912 & 0.00687 \\
\hline $\begin{array}{c}\text { Current peak value } \\
\text { when } \boldsymbol{T}_{\mathbf{e}}=\boldsymbol{T}_{\mathbf{s}}(\mathbf{A})\end{array}$ & 101.5 & 187.5 & 248 & 280 & 339 & 367.3 & 381 & 403.5 & 493.4 \\
\hline Times of over-current & 1.453 & 2.51 & 3.4 & 3.86 & 4.65 & 4.83 & 5.16 & 5.33 & 7.15 \\
\hline $\begin{array}{c}\text { Max current peak value } \\
(\mathbf{A})\end{array}$ & 111 & 192 & 260 & 294.5 & 355 & 369.3 & 394 & 407 & 546 \\
\hline Max value of $\boldsymbol{T}_{\mathbf{e}}\left(\mathbf{N}^{*} \mathbf{m}\right)$ & 3586 & 6092.5 & 7410 & 7671 & 7567 & 7484 & 7275 & 7082 & 10750 \\
\hline Time to be stable (s) & 2 & 1.7 & 1.5 & 1.8 & 2.9 & 4 & 5.2 & 8 & 3 \\
\hline
\end{tabular}

\section{Conclusion}

In this paper, the soft start of motor drive inverter is studied. The calculation formula of the starting frequency is obtained through theoretical analysis. The starting frequency is calculated by combining with the actual motor parameters. The start frequency range and the maximum start torque corresponding to the start frequency are calculated. The simulation results verify the correctness of the theoretical analysis and calculation.

This paper is supported by the Science and Technology Research Program of Chongqing Municipal Education Commission (Grant No. KJZD-K202004301).

\section{References}

1. Zhang Z., Wu X.W., Qiao H.Q., and etc. (2019) Research on Discrete Variable Frequency Soft Starter. Micromotors, Vol. 52, No. 5: 63-65.

2. Zhang Z.Y. (2007) Comparing and Optimizing of the Starting Methods for Large Motors. Large Electric Machine and Hydraulic Turbine, No.3: 27-30.

3. (2006) Several Variable Frequency Speed Control Technologies. The World of Inverters, Vol. 2: 10.
4. Liu X.L. (2001) Accurate Setting of the Ratio of Voltage to Frequency. Electrotechnical Journal, Vol. 6: 21,41-42.

5. Gu C.L., Chen Q.F., Xiong Y.Q. (2001) Electromechanics. Huazhong University of Science \& Technology Press, Wuhan. 